\title{
Brazil nuts and thyroid gland
}

\section{Commentary}

The Brazil nuts or Para nuts come from a tree Bertholletia excelsa of the family Lecythidaceae grown in many parts of the Amazon, not only in Brazil. The nuts are exceptionally large in relation to other nuts, surrounded by a hard shell and grow into a round fruit like coconut. They are commercially available raw or toasted, unsalted or salted, even coating with honey or other spices and are often found in mixtures of nuts, bars, breakfast cereals, etc.

Brazil nuts are an excellent source of vegetable protein. A serving of $30 \mathrm{~g}$., consist of only six large nuts, provide many nutrients, 185 calories, 4 grams of protein and 3 grams of carbohydrates. They also offer 2 grams fiber, $5 \%$ of the RDA for calcium and $4 \%$ of the RDA for iron and are a good source of magnesium and vitamin E, too. Most of the fats in Brazil nuts belong to the "good" unsaturated fatty acids, which contribute to maintain good cardiovascular health. From the 19 grams of fat in one serving of $30 \mathrm{~g}$., the $41 \%$ are monounsaturated and the $34 \%$ are polyunsaturated fatty acids. However, Brazil nuts contain the highest amount of saturated fat than any other dry nut; a serving provides $21 \%$ of the recommended daily intake.

\section{What characterizes Brazil nuts is that they contain more selenium than any other food}

Selenium is a trance element that belongs to antioxidants, which protect us from the free radicals and have anticancer activity. The radicals are natural by products of oxygen metabolism that may contribute to chronic diseases, such as cancer and heart disease. When we consume selenium, it interacts with proteins to form new proteins, called seleno-proteins. These proteins have antioxidant properties that help to prevent cellular damage by free radicals. Of the 25 known selenoproteins, some have well-documented roles, while researchers have yet to identify the exact role of others. As a component of selenoproteins, selenium acts as antioxidant and regulates the levels of thyroid hormones, supporting the immune system. Based on the location of selenoproteins in the body, selenium may play multiple roles, from muscle metabolism to the development of sperm, etc. A diet deficient in selenium can cause pain in muscles and joints, brittle hair, and white spots on nails, etc. In the long term, deficiency in selenium may even lead to autoimmune diseases of the thyroid, such as Hashimoto's, a disease in which the body's immune system attacks to the thyroid gland. The selenium deficiency may exacerbate the effects of iodine deficiency. On the other hand, excessive intake of selenium can lead to bad breath, diarrhea and even hair loss.

The participation of selenium in the thyroid function is very important and this is indicated by the fact that it is detected at a very high density in the thyroid gland. Selenium protects the gland by free radicals and participates in the hormonal balance of T4 and T3 in the tissues. Because of the involvement of the immune system, it appears to exert beneficial effects in autoimmune thyroid diseases (Hashimoto, Graves etc.), but also to thyroid diseases, such as: diffuse and nodular goiters, thyroid cancer, N. Graves, etc., as it has proven in
Volume 4 Issue 6 - 2016

\author{
Apergi Kiriaki \\ Clinical Dietician Nutritionist, Greece \\ Correspondence: Apergi Kiriaki, Clinical Dietician \\ Nutritionist, Greece, Tel 6987/21394, \\ Email ki.apergi@icloud.com \\ Received: August II, 2016 | Published: September 22, 2016
}

researches with supplementation with selenium-methionine. At a dose of 100 micrograms daily X2.

The recommended by the European Union daily intake (RDA) has been set at $55 \mathrm{mg} /$ day. A dose of up to $200 \mathrm{mg}$ (for an adult) daily is not considered harmful and it usually does not bring any unwanted side effects, but contrary it is even considered to be very useful. An intake of $3000 \mathrm{mg}$ of selenium daily for more than 3 weeks may cause side effects, such as liver damage, graying of hair and nail loss. The ideal values, in accordance with the specialists, range from 120 to 160 or even at 200 micrograms per liter of blood.

The amount of selenium in any food plant varies depending on the levels of selenium in the soil. Brazil Nuts come from trees that thrive in the rich soil of the Amazon jungle and therefore a 30g serving, or about six nuts, contain 544 micrograms of selenium. Furthermore, because of their content of vitamin $\mathrm{E}$ by the action of selenium is enhanced, making the Brazil nut a natural "drug". While this sounds impressive, the amount of selenium in a handful of Brazil nuts is so high that one can consume too often more than the recommended serving, endangering health issues because of selenium toxicity. ${ }^{1-4}$

Other selenium sources are oysters: an oyster offer $38.2 \mathrm{mg}(55 \%$ DV), mussels and octopus with 109\% DV/100gr., lobster, crab, squid and shrimp, tuna with $92 \mathrm{mg}(131 \% \mathrm{DV})$, whole meal bread with $11,3 \mathrm{mg}(16 \% \mathrm{DV})$ per slice, the Sunflower seeds with $32 \%$ DV per $30 \mathrm{~g}$., chia seeds with $22 \%$ DV per $85 \mathrm{~g}, 63 \%$ for a beef serving of $85 \mathrm{~g}$ and $54 \%$ for a lamb serving of $85 \mathrm{gr}, 46 \%$ for chicken or turkey serving of $85 \mathrm{~g}$, while shiitake mushrooms when cooked offer $51 \%$ per cup.

The tolerable upper intake level of selenium is 400 micrograms per day for adults, while the Upper safe level for daily supplementation is approximately $200 \mathrm{mg}$.

If consummation of Brazil nuts is daily, it is very important to watch out the intake of selenium from other sources for excessive intake. 


\section{Acknowledgements}

None.

\section{Conflict of interest}

Author declares that there is no conflict of interest.

\section{References}

1. Barcza Stockler-Pinto M, Carrero JJ, De Carvalho Cardoso Weide L, et al. Effect Of Selenium Supplementation Via Brazil Nut (Bertholletia Excelsa, Hbk) On Thyroid Hormones Levels In Hemodialysis Patients: A Pilot Study. Nutr Hosp. 2015;32(4):1808-1812.
2. Carvalho RF, Huguenin GV, Luiz RR, et al. Intake of partially defatted Brazil nut flour reduces serum cholesterol in hypercholesterolemic patients--a randomized controlled trial. Nutr J. 2015;14:59.

3. Mori SA. Sustainable Harvest and Marketing of Rain Forest Products. The Brazil Nut Industry --- Past, Present, and Future. In: Plotkin M, Famolare L, editors. USA: Island Press; 1992.

4. https://ndb.nal.usda.gov/ndb/ 